\title{
Sonic Hedgehog Acts as a Negative Regulator of $\beta$-Catenin Signaling in the Adult Tongue Epithelium
}

\author{
Fabian T. Schneider, ${ }^{*}$ Anne Schänzer, ${ }^{*}$ \\ Cathrin J. Czupalla, ${ }^{*}$ Sonja Thom,${ }^{*}$ Knut Engels, ${ }^{\dagger}$ \\ Mirko H.H. Schmidt, ${ }^{*}$ Karl H. Plate, ${ }^{*}$ \\ and Stefan Liebner* \\ From the Institute of Neurology (Edinger-Institute)," and \\ Senckenberg Institute for Pathology, Johann Wolfgang \\ Goethe-University Medical School, Frankfurt, Germany
}

Wnt/ $\beta$-catenin signaling has been implicated in taste papilla development; however, its role in epithelial maintenance and tumor progression in the adult tongue remains elusive. We show Wnt/ $\beta$-catenin pathway activation in reporter mice and by nuclear $\beta$-catenin staining in the epithelium and taste papilla of adult mouse and human tongues. $\beta$-Catenin activation in $\mathrm{APC}^{\mathrm{min} /+}$ mice, which carry a mutation in adenomatous poliposis coli $(A P C)$, up-regulates Sonic hedgehog (Shh) and Jagged-2 (JAG2) in the tongue epithelium without formation of squamous cell carcinoma (SCC). We demonstrate that Shh suppresses $\beta$-catenin transcriptional activity in a signaling-dependent manner in vitro and in vivo. A similar regulation and function was observed for JAG2, suggesting that both pathways negatively regulate $\beta$-catenin, thereby preventing SCC formation in the tongue. This was supported by reduced nuclear $\beta$-catenin in the tongue epithelium of Patched $^{+/-}$ mice, exhibiting dominant active Shh signaling. At the invasive front of human tongue cancer, nuclear $\beta$-catenin and Shh were increased, suggesting their participation in tumor progression. Interestingly, Shh but not JAG2 was able to reduce $\beta$-catenin signaling in SCC cells, arguing for a partial loss of negative feedback on $\beta$-catenin transcription in tongue cancer. We show for the first time that the putative Wnt/ $\beta$-catenin targets Shh and JAG2 control $\beta$-catenin signaling in the adult tongue epithelium, a function that is partially lost in lingual SCC. (Am J Pathol 2010, 177:404-414; DOI: 10.2353/ajpath.2010.091079)

The Wnt/ $\beta$-catenin and the hedgehog $(\mathrm{Hh}) / \mathrm{Gli}$ pathways are essential for various developmental processes, and their adult deregulation has been implicated in several pathologies, namely cancer and neurodegenerative diseases (for review see Clevers ${ }^{1}$ and Ingham ${ }^{2}$ ).

The key protein in "canonical" Wnt signaling is $\beta$-catenin, which acts as a transcription factor with members of the lymphoid enhancer factor (Lef)/T-cell factor family. ${ }^{3}$ On Wnt ligand-mediated activation of a receptor complex formed by frizzled and low-density lipoprotein receptorrelated protein $5 / 6$, proteasomal degradation of $\beta$-catenin is inhibited by inactivating the destruction complex assembled by glycogen synthase kinase $3 \beta$ (GSK3 $\beta$ ), adenomatous poliposis coli (APC), and axin. ${ }^{1}$ Consequently, $\beta$-catenin circumvents ubiquitinylation and subsequent destruction, favoring its transcriptional activity together with Lef/T-cell factor.

In the adult, Wnt signaling participates in the maintenance of several tissues, such as crypt cells of the colon, endosteal cells of the bone marrow, the hair bulge stem cell niche, and the hippocampal dentate gyrus. ${ }^{4-6}$ In these tissues activation of the Wnt pathway likely plays a role in stem or progenitor cell maintenance. ${ }^{7}$ Overactiva-

Supported by the Deutsche Forschungsgemeinschaft grant P1 158/7-3 (Research Group 510 Vascular Homeostasis), the SFB/TR23 grant B7 (Vascular Differentiation and Remodeling), the Excellence Cluster CardioPulmonary System, the LOEWE Initiative Hessen, (Onkogene Signaltransduktion Frankfurt (OSF); III L 4-518/55.004, 2009), and the EU FP7 grant JUSTBRAIN

Accepted for publication March 9, 2010.

F.T.S. performed most of the experiments, participated in the study design, and helped to draft the article. A.S. participated in human sample preparation and performed statistical analysis. C.J.C. participated in the qRT-PCR analyses. S.T. performed the immuno staining and in situ hybridizations. K.E. was involved in human sample acquisition and diagnostic. M.H.H.S. participated in reporter assays and helped to draft the article. K.H.P. participated in its design and coordination. S.L. conceived of the study and participated in its design and coordination and drafted the article. All authors read and approved the final article.

Supplemental material for this article can be found on http://ajp. amjpathol.org

Current address of A.S.: Institute of Neuropathology, Justus LiebigUniversity Medical School, Giessen, Germany.

Address reprint requests to Dr. Stefan Liebner, Institute of Neurology (Edinger-Institute), ${ }^{*}$ Johann Wolfgang Goethe-University Medical School, Theodor-Stern-Kai 7, 60590 Frankfurt, Germany. E-mail: stefan.liebner@ kgu.de. 
tion of "canonical" Wnt signaling in the adult is an initial step to neoplasia, as known to be the case in familial adenomatous poliposis. In familial adenomatous poliposis and in $\mathrm{APC}^{\mathrm{min} /+}$ mice, the corresponding mouse model, one allel of the tumor suppressor gene APC is mutated, leading to diminished $\beta$-catenin degradation and, therefore, to increased signaling. ${ }^{1}$ Hence the Wnt pathway requires tight regulation.

Interestingly, the Wnt and the Sonic hedgehog (Shh) pathways were described to have distinct and reciprocal, repressive function in various tissues. ${ }^{8}$ In mammals there are three members of the Hh family: Indian hedgehog, Desert hedgehog, and Shh of which Shh has the most prominent developmental effect. ${ }^{9}$ In the absence of $\mathrm{Hh}$ ligand, patched (Ptch), a 12-transmembrane spanning protein, represses smoothened (SMO) thereby inhibiting Hh signaling. SMO, like the frizzleds, is a member of the 7-transmembrane spanning G-protein-coupled receptorlike superfamily and transduces the $\mathrm{Hh}$ signal form the plasma membrane to the cytoplasm. On Hh binding to Ptch its repressive function on SMO is released, ${ }^{10}$ thereby activating Gli1/2 dependent transcription. In the repressive state Gli1/2 proteins are phosphorylated by GSK $3 \beta$, CK1, and PKA, promoting the ubiquitination and thereby the degradation of Gli1/2. ${ }^{2}$

Similar to the Wnt/ $\beta$-catenin pathway, Shh signaling requires tight regulation as it has been implicated in tumorigenesis in particular in the skin and the cerebellum of the brain. ${ }^{11}$ Although the Wnt and Shh pathways were implicated in the formation of various cancers, their role in the oral tongue epithelium and hence in lingual squamous cell carcinoma (LSCC) remains elusive.

Expression of Shh and its receptor Ptch was detected in the developing tongue taste papilla, ${ }^{12,13}$ and subsequently the importance of a functional Shh signal during embryonic mouse taste bud development was shown. ${ }^{14}$ Recently, $\beta$-catenin/Wnt signaling was identified in developmental placode and taste papilla formation in the tongue, establishing this pathway as an upstream factor of Shh, Sox2, and BMP4 in this tissue. ${ }^{15-17}$

Here we show activation of the canonical Wnt pathway during tongue epithelial turnover in the healthy mouse and human. We provide evidence that the increase in $\beta$-catenin transcriptional activity in $\mathrm{APC}^{\mathrm{min} /+}$ mice upregulates Shh, Jagged-2 (JAG2), and Notch2 without affecting epithelial morphology and homeostasis. Shh and JAG2 are involved in down-regulating $\beta$-catenin sig- naling, thus participating in counterbalancing activation of the canonical Wnt pathway. In samples of human LSCC (hLSCC), nuclear $\beta$-catenin and cytoplasmic Shh are frequently detected at the invasive front, correlating with tumor grade and proliferation. Although Shh inhibits $\beta$-catenin signaling in an hLSCC cell line, JAG2-mediated down-regulation of $\beta$-catenin signaling was abolished in these cells. This suggests that the concomitant repression of $\beta$-catenin signaling by Shh and JAG2 are required to control epithelial homeostasis and to prevent cancer formation.

\section{Materials and Methods}

\section{Mice and Tissue Preparation}

BAT-gal reporter mice have been provided by Stefano Piccolo (Padua, Italy), ${ }^{6}$ and C57BL/6J-Apc ${ }^{\mathrm{Min}} / \mathrm{J}\left(\mathrm{APC}^{\mathrm{min} /+}\right.$ ) by Markus F. Neurath (Mainz, Germany). Offspring was genotyped by genomic PCR from tail biopsy. Ptch $^{+/-}$mice were kept in a C57BL/6J background as described previously. ${ }^{11}$ Adult mice were anesthetized with isofluorane and subsequently sacrificed by cervical dislocation.

\section{Human Sample Preparation}

Biopsies were collected randomly from 19 patients with LSCC at the Department of Pathology, Frankfurt University Hospital (15 male patients; average age, 56.8 years; four women; average age, 87 years). The age of the patients varied between 41 and 96, with a mean of 66.6 years of age. According to World Health Organization tumor classification, tumors were classified as grade I $(n=3)$, grade II $(n=13)$, and grade III $(n=3$; Supplemental Table T1, see http://ajp.amjpathol.org). Use of archival specimen was approved by the Ethical Committee of Surgery, Frankfurt University Hospital, Frankfurt/Main, Germany. For analysis of human tongue, papillae postmortem specimens were used. Immunohistochemical staining of the formalin fixed, paraffin embedded tissue was performed according to standard procedures.

\section{Antibodies and Immunostaining}

Nuclei were counterstained with TOTO-3 (Molecular Probes, Eugene, OR; Table 1). Histology and eosin counterstaining on paraffin sections was according to stan-

Table 1. List of Primary Antibodies

\begin{tabular}{llll}
\hline \multicolumn{1}{c}{ Antigen } & Host & Dilution & \\
\hline Anti-HA high affinity antibody & Rat & $1: 500$ & Manufacturer \\
Cleaved-caspase-3 & Rabbit & $1: 100$ & Roche Diagnostics, Mannheim, Germany \\
Cytokeratin 5/6 & Mouse & $1: 50$ & Chemicon International Inc., Temecula, CA \\
Cytokeratin Endo-A (TROMA-I) & Rat & $1: 200$ & Developmental Studies Hybridoma Bank, lowa City, IA \\
G $\alpha$-gustducin & Rabbit & $1: 200$ & Santa Cruz Biotechnology, Santa-Cruz, CA \\
Ki67 antigen (M7249) & Rat & $1: 50$ & Dako Denmark, Glostrup, Denmark \\
Notch2 & Rat & $1: 200$ & Developmental Studies Hybridoma Bank \\
PLC $\gamma 2$ & Rabbit & $1: 200$ & Santa Cruz Biotechnology, Santa Cruz, CA \\
Shh & Goat & $1: 50$ & R\&D Systems, Minneapolis, MN \\
$\beta$-catenin (clone 14) & Mouse & $1: 200$ & BD Biosciences, San Jose, CA \\
$\beta$-galactosidase & Rabbit & $1: 1000$ & Abcam, Cambridge, UK \\
\hline
\end{tabular}


dard procedures. For immunofluorescent staining, unfixed samples were embedded in TissueTek OCT (Sakura Finetech Europe B.V., Zoeterwoude, NL), sectioned, and labeled as described previously. ${ }^{18}$

Fluorescence was observed with an epifluorescence microscope (Nikon 80i; Nikon, Tokyo, Japan) and documented with a digital camera (DS-5Mc; Nikon), or with a confocal microscope (Nikon C1si; Nikon). Images were computer processed by using ImageJ (National Institutes of Health, Bethesda, MD) and Adobe Photoshop CS3 for Macintosh.

\section{Whole Mount $\beta$-Galactosidase Staining of Mouse Tongues}

Tongues from BAT-gal mice were fixed in 4\% paraformaldehyde, permeabilized in PBS (0.02\% NP-40). Staining in potassium ferri-cyanide solution was performed over night at $4^{\circ} \mathrm{C}$ and additional 5 hours at room temperature. Samples were photographed and subjected to standard embedding procedures for paraffin or cryostat sectioning.

\section{In Situ Hybridization}

Mouse Jagged-2 cDNA was kindly provided by Verdon Taylor (University of Sheffield, Sheffield, UK), and mouse Shh cDNA was obtained from imaGenes (imaGenes $\mathrm{GmbH}$, Berlin, Germany). In situ hybridization analysis was performed by standard procedures. Briefly, cryo sections were fixed in $4 \%$ paraformaldehyde, dehydrated in an ascending alcohol series, air dried, and refrozen at $-70^{\circ} \mathrm{C}$.

To inactivate endogenous alcaline phosphatases and basic proteins, the sections were incubated with $0.2 \mathrm{M}$ $\mathrm{HCl}$, washed, and proteins were denatured by proteinase $\mathrm{K}(10 \mu \mathrm{g} / \mathrm{ml})$. Proteinase $\mathrm{K}$ was inactivated with $0.1 \mathrm{M}$ Glycin, and slides were rinsed and refixed in $4 \%$ paraformaldehyde. Titration of $625 \mu$ acetic anhydride in 250 $\mathrm{ml} 0.1 \mathrm{M}$ triethanolamine prehybridization in premix (for $10 \mathrm{ml}$ : $5 \mathrm{ml}$ de-ionized formamide, $2 \mathrm{ml} 20 \times$ standard saline citrate, $1 \mathrm{ml} 50 \%$ dextransulfate, $1 \mathrm{ml} 50 \times$ Denhardt's, $0.05 \mathrm{ml} 20 \%$ SDS, t-RNA [10 mg/ml] $0.25 \mathrm{ml}$ ) for 5 hours at room temperature. The probes were diluted 1:20 in premix and heated to $95^{\circ} \mathrm{C}$, cooled down to $48^{\circ} \mathrm{C}$, and incubated over night at $68^{\circ} \mathrm{C}$. The next day, slides were rinsed twice in standard saline citrate at $70^{\circ} \mathrm{C}$ and twice standard saline citrate at room temperature. Incubation in dioxygenin-1 (DIG1, Roche, Mannheim, Germany) was followed by blocking in DIG2 (Roche, Mannheim, Germany). Primary antibody was diluted 1:500 in DIG2 and incubated for 1 hour at room temperature, rinsed three times in DIG1, and 1 time in DIG3. Staining solution (polyvenyl alcohol, DIG3, and 4-nitroblue-tetrazolium-[5-bromo-4-chloro-3-indolylphosphate]) was incubated over night at $30^{\circ} \mathrm{C}$, followed by 10 washes in PBS. Slides were counterstained by hematoxylin and mounted in Aqua Polymount.

\section{Quantitative RT-PCR}

The tongue epithelial layer was dissected from 5-monthold APC ${ }^{\mathrm{min} /+}$ mice and control litters, and total RNA was extracted in guanidium solution (4 M Guanidine Thiocyanate, $0.5 \% \mathrm{~N}$-Lauroylsarcosine sodium salt, $25 \mathrm{mmol} / \mathrm{L}$ tri-Sodium Citrate 2-hydrate, $0.1 \mathrm{mmol} / \mathrm{L}$ 2-Mercaptoethanol), centrifuged o.n. over a cesium-chloride gradient $\left(18^{\circ} \mathrm{C} / 28,000 \mathrm{rpm} / \mathrm{min} / 16\right.$ hours; SW41Ti; Beckman Coulter), precipitated in sodium-acetate, and resuspended in RNase-free water. ${ }^{19}$

RT-PCR was performed with the First Strand cDNA Sythesis Kit (Fermentas GmbH, St. Leon-Rot, Germany) by using $1 \mu \mathrm{g}$ total RNA per reaction. Resulting cDNA was digested with RNase H (Roche Diagnostics $\mathrm{GmbH}$ ). For quantitative RT-PCR (qRT-PCR), Absolute QPCR SYBR Green Fluorescein Mix (ThermoFisher Scientific, Waltham, MA) was used according to the manufacturer's protocol.

qRT-PCR conditions were as follows: 15 minutes at $95^{\circ} \mathrm{C}, 45$ cycles of 30 seconds at $95^{\circ} \mathrm{C}, 30$ seconds at $62^{\circ} \mathrm{C}$, and 35 seconds at $72^{\circ} \mathrm{C}$ in a BioRad MyiQ RealTime PCR Detection System (Bio-Rad Laboratories, Hercules, CA). Raw data were analyzed with iQ5-Standard Edition software (Bio-Rad Laboratories, Hercules, CA).

Primers used were as follows: Shh (sense 5'-TGGAAGCAGGTTTCGACTGG-3'; antisense 5'-GGAAGGTGAGGAAGTCGCTGT-3'); Gli1 (sense 5'-CCTTTAGCAATGCCAGTGACC-3'; antisense 5'-GAGCGAGCTGGGATCTGTGTAG-3'); patched homolog 1 (Ptch1; sense 5'-TTGGGATCAAGCTGAGTGCTG-3'; antisense 5'-CGAGCATAGCCCTGTGGTTCT-3'); Jagged-2 (sense 5'-TTCCTGGATGGAGACTGCAAC-3'; antisense 5'-CTGACCAGAGAGCAGGCAAGG-3'); and Notch2 (sense 5'-GCCAACTGCACCTCCACTCTT-3'; antisense 5'-AGCCACACTCCTCGCTGTTG-3') in murine tongue samples.

The expression was analyzed with GraphPad Prism 5.0 for Macintosh (GraphPad Software, LaJolla, CA). Samples were normalized by the expression of RNA-polymerase II (MGl: 98086) and G6PDX (MGl:105979) and shown as percentage of control.

\section{Quantification of $\beta$-Catenin Positive Nuclei}

Paraffin sections stained for $\beta$-catenin were photographed with a $40 \times$ objective. For each tongue (APC ${ }^{\mathrm{min} /+}$ and $\mathrm{APC}^{+/+}, \mathrm{Ptch}^{+/-}$and $\mathrm{Ptch}^{+/+} n=3$ ), six slices were counted, and raw data were analyzed with GraphPad Prism 5.0 for Macintosh. Statistical analysis was performed by using the unpaired, two-sided $t$-test (Student's $t$-test) between the groups. Significant differences were assumed at a level of $P<0.05$. The data are expressed as mean values \pm SEM. The same procedure was used for the quantification for Ki-67 and terminal deoxynucleotidyl transferase-mediated dUTP nick-end labeling (TUNEL) assays.

\section{Cell Culture and Reporter Gene Assays}

Luciferase assay was preformed according to the protocol of Dyer et al. ${ }^{20}$ HEK293 cells were seeded in 24-well plates and transfected by the calcium-phosphate method with the following plasmids for canonical Wnt signaling: super( $8 \times)$ TOP-FLASH or super(8X)FOP-FLASH (generous gifts from Dr. R. Moon, University of Washington 
School of Medicine, Seattle, WA) and pRL-CMV (Promega, Madison, WI). For Hh signaling, cells were either transfected with the $8 \times 3^{\prime}$ Gli-BS 851 Lucll or the $8 \times$ 3'GliM3-BS 851 Lucll (generous gifts from Dr. Hiroshi Sasaki, Center of Developmental Biology, RIKEN Kobe, Japan) and pRL-CMV. If desired, cells were also transfected with 500 ng mouse (m) Shh-pCMVSport6.1 (imaGenes), 300 ng pcDNA3.1-mNotch2, 600 ng pcDNA3.1ratJAG2, $250 \mathrm{ng}$ of pcDNA3.1-HisB-Gli1 (generous gift from Dr. Hiroshi Sasaki, Center of Developmental Biology, RIKEN Kobe, Japan), or 50 ng pCS2+-LEF $\Delta N-\beta C T A$ (generous gift from Dr. A. Hecht, Freiburg, Germany). The concentrations of all transfections were brought up to the same level of DNA with the vector pTRE2hyg (ClontechTakara Bio Europe, Saint-Germain-en Laye, France) or pcDNA3.1/Hygro (+) (Invitrogen, Carlsbad, CA). After 24 hours, cells were stimulated with $20 \mathrm{mmol} / \mathrm{L} \mathrm{LiCl}$, Shh-conditioned medium (CM), control-CM, $10 \mu \mathrm{mol} / \mathrm{L}$ cyclopamine (Calbiochem, Darmstadt, Germany), 5 to $10 \mu \mathrm{mol} / \mathrm{L}$ dimethyl sulfoxide, or 5 to $10 \mu \mathrm{mol} / \mathrm{L} \gamma$-secretase inhibitor $\mathrm{N}$-[N-(3,5-Difluorophenacetyl)-L-alanyl]-S-phenylglycine t-butyl ester (DAPT) (Sigma, Munich, Germany). Twentyfour hours later, cells were washed in PBS and lysed, and luciferase activity was determined on a Berthold Lumat LB 9507 luminometer (Berthold Technologies GmbH \& Co KG, Bad Wildbad, Germany). Luciferase activity was normalized to TK-renilla luciferase, and values were blotted as fold induction to the control values. Three independent experiments are shown as averages with SEM.

\section{Western Blot Analysis}

HEK293 cells $\left(3 \times 10^{5}\right)$ were seeded on a 6-well plate. After 24 hours, cells were transfected with $5.5 \mu \mathrm{g}$ of pCMV-Sport6.1-Shh, pcDNA3.1-Jagged2, pcDNA3.1Notch2, or pcDNA3.1/hygro (+) plasmids. Forty-eight hours after transfection, cells were washed two times in ice cold PBS, scraped in ice-cold lysing buffer $(50 \mathrm{mmol} / \mathrm{L}$ TricHCl; $150 \mathrm{mmol} / \mathrm{L} \mathrm{NaCl}$; 1\% NP-40 [Igepal Ca-630]; $0.5 \%$ Sodium deoxycholate; $0.5 \%$ SDS; 1 mmol/L EDTA; and $1 \mathrm{mmol} / \mathrm{L}$ phenylmethylsulfonyl fluoride; Complete Mini, Roche Diagnostics GmbH, Mannheim, Germany), and centrifuged for 10 minutes at 13,000 rpm. Total extracts were separated by $7 \%$ or $12 \%$ SDS-polyacrylamide gel electrophoresis and analyzed in immunoblot with specific antibodies according to standard procedures.

\section{Results}

Wnt/ $\beta$-Catenin Signaling Is Active in the Adult Mouse Tongue Epithelium and Is Elevated in APC $^{\mathrm{min} /+}$ Mice

To investigate the canonical Wnt pathway in adult mice, we performed LacZ staining in BAT-gal reporter mice, demonstrating activation of the Wnt pathway in some fungiform and, most prominent, in filiform papilla that was corroborated by nuclear $\beta$-catenin staining (Supplemental Figure S1, see http://ajp.amjpathol.org).
As dominant activation of the canonical Wnt pathway plays a role in tumor formation, we asked whether APC $\mathrm{Pin}^{\mathrm{m}+}$ mice exhibit alterations of epithelial and taste papilla turnover in the tongue. The frequency of nuclear $\beta$-catenin in the tongue epithelium of APC ${ }^{\mathrm{min} /+}$ mice was significantly increased compared with littermate controls (Figure $1 \mathrm{~A}$ and $\mathrm{D} ; \mathrm{G}$ and $\mathrm{J}$; quantification in $\mathrm{M},{ }^{* \star} P<0.005$ ).

To evaluate proliferation, tongues of $\mathrm{APC}^{\mathrm{min} /+}$ mice were sectioned and stained for the proliferation marker $\mathrm{Ki}-67$. The quantification of $\mathrm{Ki}-67$ positive cells revealed no significant difference between $\mathrm{APC}^{\mathrm{min} /+}$ mice and controls (Figure 1B, E, H, K, and N), also apoptosis did not significantly differ, as evaluated by TUNEL staining (Figure 1C, F, I, L, and N) and staining for active caspase-3 (Supplemental Figure S2, see http://ajp.amjpathol.org).

We further addressed the question if the increase in $\beta$-catenin signaling affects the morphology and cellular architecture of the tongue epithelium in general and the taste buds (TB) in particular. Confocal analysis of staining against $\alpha$-Gustducin and the TB specific phospholipase $\mathrm{C} \beta 2$, as well as scanning electron microscopy, did not reveal any alterations in fungiform papilla of $\mathrm{APC}$ min/+ mice versus wild-type (Supplemental Figure S3, see http://ajp.amjpathol.org). Furthermore, we investigated tongue histology by H\&E staining and evaluated the morphology of epithelial layers by morphometric analysis, which did not reveal significant differences between wildtype and $\mathrm{APC}^{\mathrm{min} /+}$ mice (data not shown).

To understand the effect of constitutive $\beta$-catenin activation on other pathways involved in tongue epithelial development and maintenance, we investigated the expression and distribution of Shh, which plays an antagonistic role during embryonic tongue development on Wht signaling.

\section{Shh Is Up-Regulated in APC min/+ Mice and Negatively Regulates Wnt Pathway Activity}

Immunohistochemical staining of Shh was stronger in the epithelium of $\mathrm{APC}^{\mathrm{min} /+}$ mice compared to controls (Figure 2, A-D). In situ hybridization (Figure 2, E and F) and qRT-PCR (Figure 2G) corroborated the up-regulation on the mRNA level, suggesting that the increase in nuclear $\beta$-catenin correlates with an up-regulation of Shh. Furthermore, Ptch1, which is a known downstream target of Shh, was also significantly up-regulated in $\mathrm{APC}$ min/+ tongues $\left({ }^{\star \star} P<0.005\right)$, indicating increased $\mathrm{Hh}$ signaling activity (Figure 2G), whereas Gli1 mRNA was not effected.

To understand the influence of Shh on $\beta$-catenin transcriptional activity when the degradation complex is inhibited, which is the case in $\mathrm{APC}^{\mathrm{min} /+}$ mice, we investigated superTOP-FLASH or mutant superFOP-FLASH reporter activity in HEK293 cells in vitro. Cells were transfected with the superTOP/FOP-FLASH reporter constructs and with increasing amounts of the control vector or mShh (1 to $1000 \mathrm{ng} \mathrm{cDNA}$ ), respectively. Transcriptional activation of $\beta$-catenin was stimulated with 20 $\mathrm{mmol} / \mathrm{L} \mathrm{LiCl}$, which blocks GSK3 $\beta$ enzymatic activity. Shh inhibited superTOP-FLASH activation in LiCl stimulated 

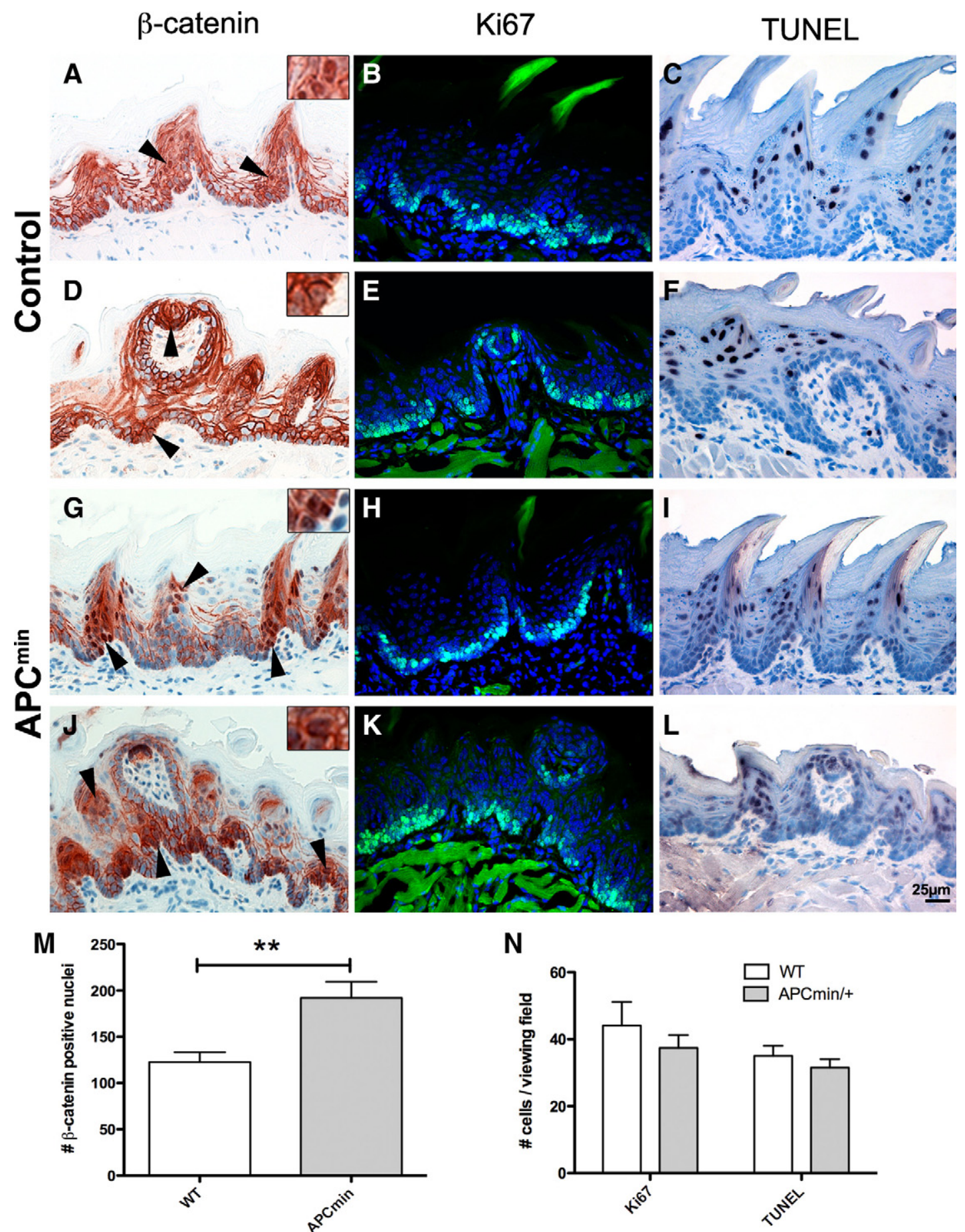

Figure 1. Increased nuclear $\beta$-catenin in the tongue epithelium of $\mathrm{APC} \min /+$ mice. $\mathbf{A}, \mathbf{D}, \mathbf{G}$, and $\mathbf{J}$ : The tongue epithelium of $\mathrm{APC}$ min/ $+\mathrm{mice}(\mathbf{G}$ and $\mathbf{J}) \operatorname{shows}$ increased nuclear localization of $\beta$-catenin compared with controls (A and $\mathbf{D})$. Note that positive nuclei are located in the epithelium and in taste buds, arrowheads point to nuclear $\beta$-catenin. M: Quantification of $\beta$-catenin positive nuclei in $\mathrm{APC}^{\min /+}$ compared with wild-type (WT) mice $\left({ }^{* *} P<0.005\right)$. B, E, H and K: Cell proliferation was not altered in $\mathrm{APC}^{\mathrm{min} /+}$ mice $(\mathbf{H}$ and $\mathbf{K})$ compared with controls $(\mathbf{B}$ and $\mathbf{E})$, determined by Ki- 67 antigen immunofluorescence. $\mathbf{C}$, $\mathbf{F}, \mathbf{I}$, and $\mathbf{L}$ : apoptosis was not significantly altered in the tongue epithelium of $\mathrm{APC}^{\mathrm{min} /+}$ mice $(\mathbf{I}$ and $\mathbf{L})$ compared with wild-type $(\mathbf{C}$ and $\mathbf{F})$ as evaluated by TUNEL staining. N: Combined graph showing quantification of Ki-67 and TUNEL positive cells in $\mathrm{APC}^{\mathrm{min} /+}$ mice compared with wild-type. For statistical analysis, three animals of each genotype were analyzed for nuclear $\beta$-catenin, Ki-67, and TUNEL staining.

HEK293 cells in a dose-dependent manner, reaching maximal inhibition at $250 \mathrm{ng}$ cDNA (Figure 3A). To proof the specific effect of Shh, we confirmed the expression of the protein by Western blot in transfected cells and evaluated activation of canonical Shh signaling by $8 \times 3^{\prime} \mathrm{Gli}-$
Lucll reporter assay ${ }^{21}$ (Figure 3B). mGli1 transfection resulted in significant reporter induction and served as a positive control. Transfected Shh showed only a moderate induction after 24 hours, whereas Shh-CM elicited significant reporter activation. As GSK3 $\beta$ inhibition by 


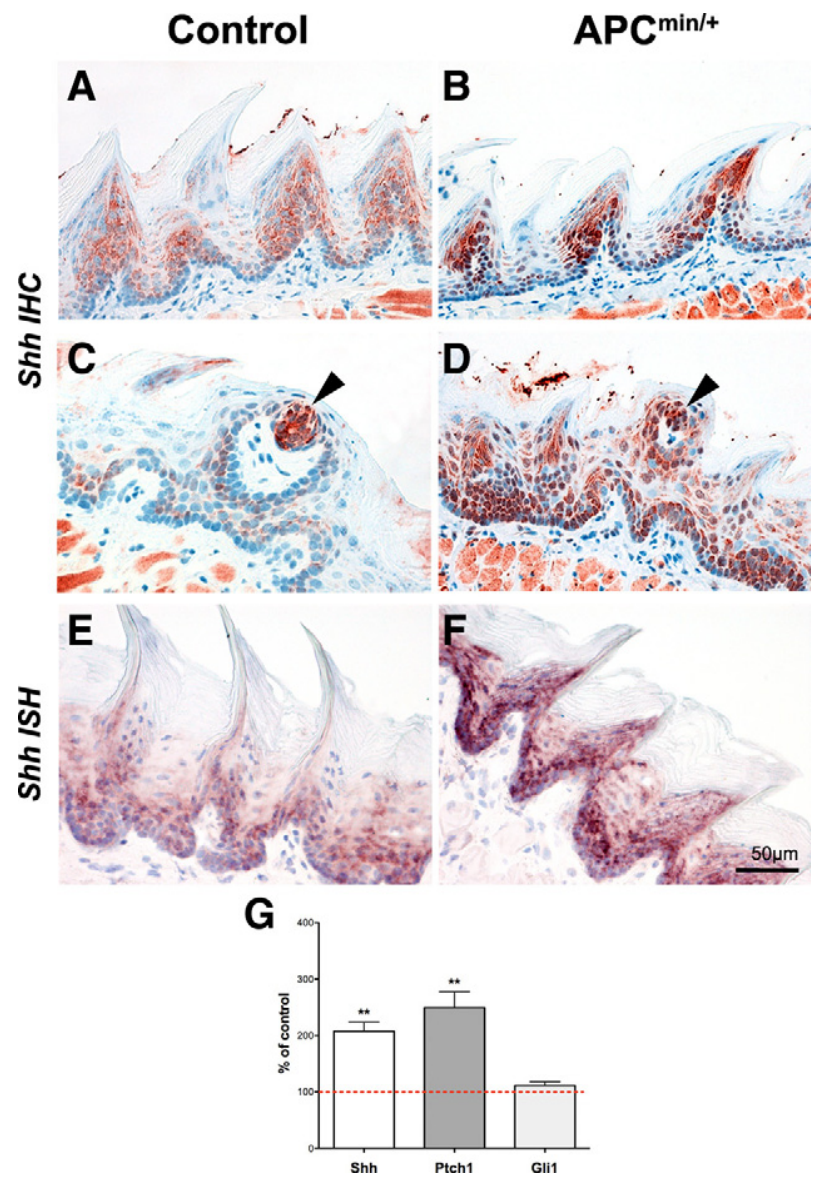

Figure 2. Shh and the Hh target gene Ptch1 are up-regulated in $\mathrm{APC}^{\mathrm{min} /+}$ tongue epithelium. $\mathbf{B}, \mathbf{D}$, and $\mathbf{F}$ : Shh is augmented in papillae of $\mathrm{APC}^{\mathrm{min} /+}$ mice compared with controls (A, C, and $\mathbf{E}$ ) as revealed by immunohistochemistry (A-D) and in situ hybridization ( $\mathbf{E}$ and $\mathbf{F}$ ), respectively. Arrowheads indicate Shh positive cells in the fungiform papilla. G: Quantitative real-time PCR $(n=3)$ for Shh, Ptch1, and Gli1 revealed significant up-regulation of Shh and Ptch1 in $\mathrm{APC}^{\mathrm{min} /+}$ mice, whereas Gli1 was not altered $(n=3$ tongue epithelia of $\mathrm{APC}^{\mathrm{min} /+}$ and wild-type) ( $\left.{ }^{* *} P<0.005\right)$. Data are normalized against G6PDX and polr2a. Control values were set to $100 \%$ (dashed line).

$\mathrm{LiCl}$ may also interfere with the signaling of other pathways such as Shh, we made use of a Lef- $1-\beta$-catenin fusion construct (Lef $\Delta \mathrm{N}-\beta \mathrm{CTA}$ ), conferring dominant activation of $\beta$-catenin-dependent signaling without interfering with the endogenous $\beta$-catenin pool. ${ }^{22}$ Shh also significantly inhibited superTOP-FLASH reporter activation induced by Lef $\Delta \mathrm{N}-\beta \mathrm{CTA}$, suggesting that Shh represses $\beta$-catenin signaling at the transcriptional level, independently of the $\beta$-catenin degradation complex $\left({ }^{*} P<\right.$ 0.0147; ${ }^{\star \star} P<0.0015$; Figure $3 \mathrm{C}$ ). For Shh conditioned medium, we obtained similar results, indicating that extracellular Shh acts via a receptor-mediated pathway $\left({ }^{\star \star} P<0.002 ;{ }^{\star} P<0.0241\right.$; Figure 3D). This interpretation is supported by the finding that inhibition of canonical hedgehog signaling by the alkaloid cyclopamine (10 $\mu \mathrm{mol} / \mathrm{L}$ ), abrogated the inhibitory effect of Shh on the superTOP-FLASH reporter (Supplemental Figure S4, see http://ajp.amjpathol.org).

To understand if the Shh pathway negatively regulates $\beta$-catenin signaling in the adult tongue in vivo, we made use of Ptch heterozygous mice $\left(\mathrm{Ptch}^{+/-}\right)$that exhibit a
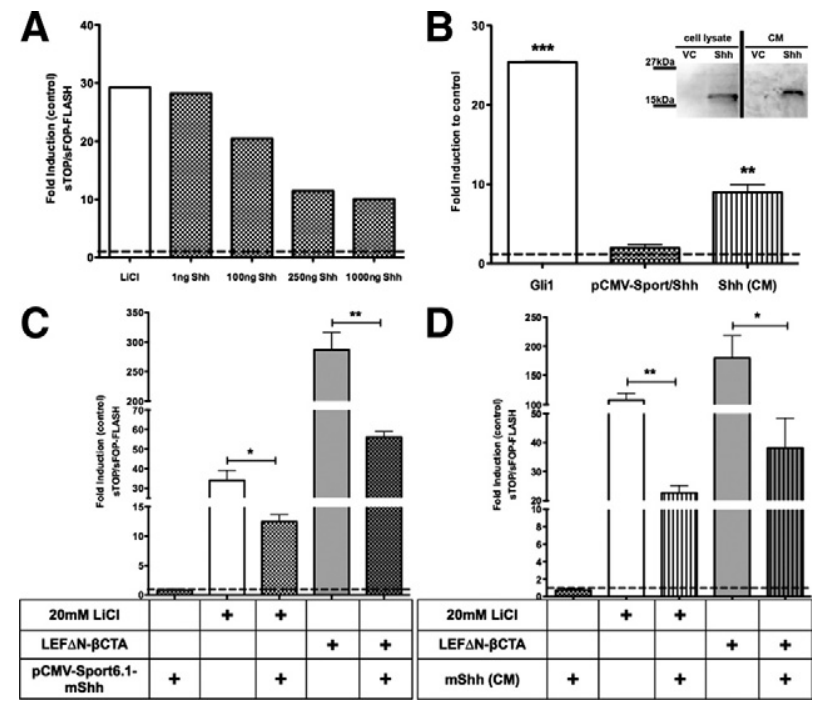

Figure 3. In vitro up-regulation of Shh inhibits sTOP/sFOP-FLASH in HEK293 cells. A: HEK293 cells were transiently transfected with the super $(8 \times)$ TOP-FLASH and the super $(8 \times)$ FOP-FLASH reporter plasmid, respectively, and stimulated with $20 \mathrm{mmol} / \mathrm{L} \mathrm{LiCl}$. After transfection with increasing amounts of pCMV-Sport6.1-Shh plasmid, activation of the STOPFLASH reporter was measured after 24 hours. B: To check the mShh biological activity in HEK293 cells transfected with the $8 \times 3^{\prime}$ Gli-BS $\delta 51$ LucII or the $8 \times 3^{\prime}$ GliM3-BS $\delta 51$ LucII luciferase reporter, after stimulation of HEK293 cells either by mGli1 transfection as a positive control or by Shh-CM, luciferase activity was measured after 24 hours $\left({ }^{* *} P<0.0081 ;{ }^{*} P<0.0157\right)$. Validation of mShh protein expression in HEK293 cells transfected with the pCMVSport6.1-Shh or vector control (VC) by Western blot analysis of cell lysate and CM on a $12 \%$ SDS-polyacrylamide gel electrophoresis. C and D: Shh effect on sTOP/sFOP-FLASH reporter in HEK293 cells. Stimulation of canonical Wnt signaling either by $20 \mathrm{mmol} / \mathrm{L} \mathrm{LiCl}$ or LEF $\Delta \mathrm{N}-\beta \mathrm{CTA}$ transfection. C: $500 \mathrm{ng}$ pCMV-Sport6.1-Shh-plasmid ( $P<0.0147$; $\left.{ }^{* *} P<0.0015\right)$ or (D) Shh-CM were used $\left(* * * P<0.002 ;{ }^{*} P<0.0241\right)$. Assays were repeated in three individual experiments; SD is shown as SEM.

dominant activation of Shh signaling and evaluated the incidence of nuclear $\beta$-catenin in the tongue epithelium in comparison with wild-type mice (Figure 4, A-D). The number of $\beta$-catenin positive nuclei in $\mathrm{Ptch}^{+/-}$tongues was significantly decreased compared to wild-type controls (Figure 4I).

Shh ligand appeared to be decreased in immunohistochemical staining (Figure 4, E-H). This was confirmed on the mRNA level by qRT-PCR $\left({ }^{\star \star \star} P<0.0001\right)$, whereas Gli1 was significantly up-regulated ( $\left.{ }^{\star} P<0.0187\right)$ and the Shh target gene Ptch1 was not regulated compared to wild-type (Figure 4J). This suggests that dominant active Shh signaling dampened $\beta$-catenin nuclear translocation and therefore, its signaling activity in the epithelium of Ptch heterozygous tongues. Whether the differential regulation of $\beta$-catenin and Shh signaling plays a role in the human tongue, we investigated postmortem tongue tissue of normal and tumor bearing tongues.

\section{Human Squamous Cell Carcinomas Show Nuclear Accumulation of $\beta$-Catenin and Up-Regulation of Shh}

First we confirmed that nuclear $\beta$-catenin and Shh are also present in the healthy human tongue epithelium (Supplemental Figure S5, see http://ajp.amjpathol.org). To 


\section{Control}

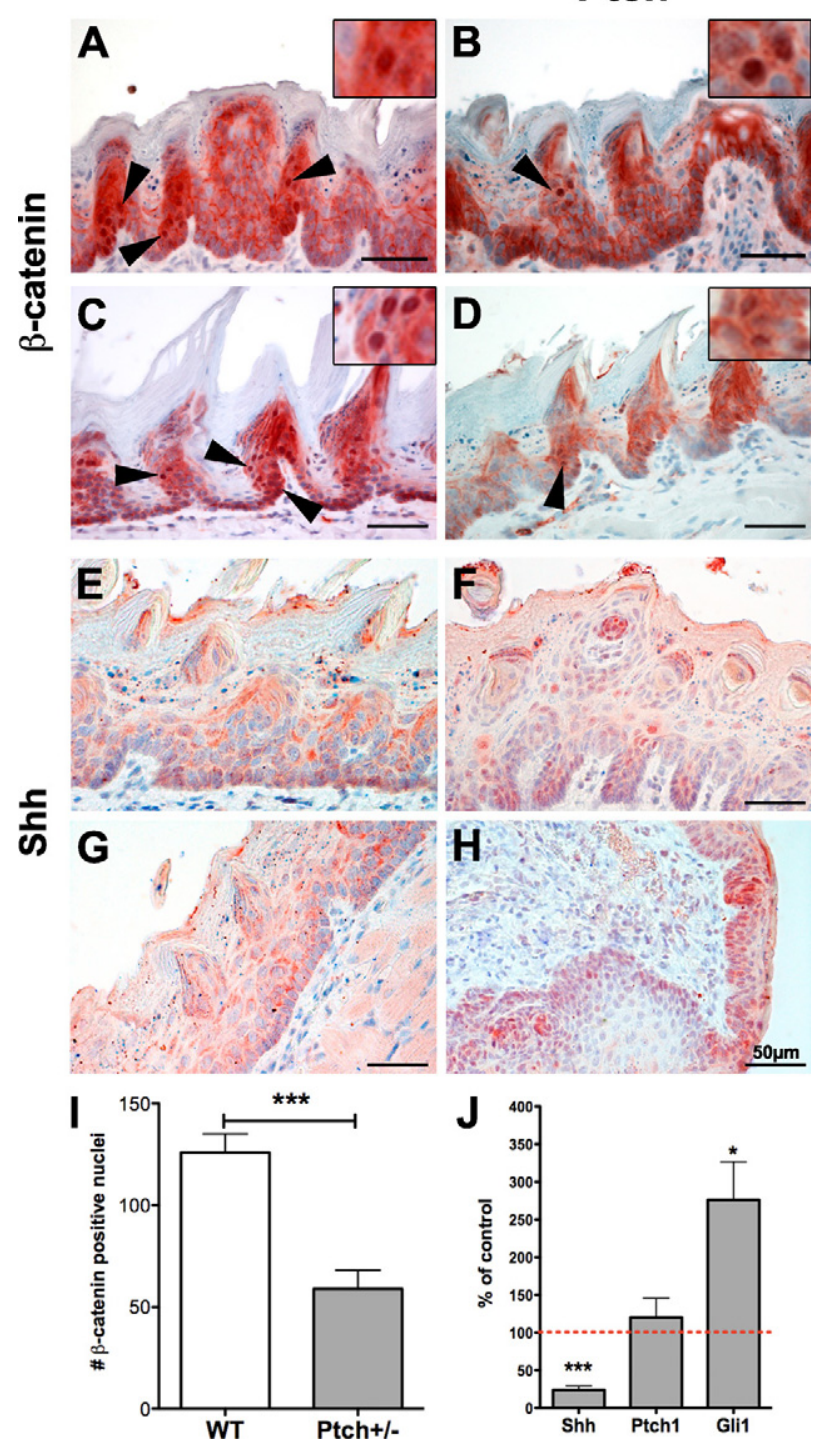

Figure 4. Expression of Shh and nuclear $\beta$-catenin is down-regulated in $\mathrm{Ptch}^{+/-}$animals compared with wild-type. A-D: $\mathrm{Ptch}^{+/-}$mice showed reduced levels of nuclear $\beta$-catenin $(\mathbf{B}$ and $\mathbf{D})$ compared with control animals (A and $\mathbf{C} ; n=3$ ); arrowheads point to nuclear $\beta$-catenin; insets show higher magnification. Quantification of nuclear $\beta$-catenin staining (I) showed a highly significant reduction in $\mathrm{Ptch}^{+/-}$mice tongue epithelium ${ }^{{ }^{*} * * * *} P<$ 0.0001; SD is shown as SEM). $\mathbf{E}-\mathbf{H}$ : Shh was reduced evidenced by IHC in the tongue epithelium of $\mathrm{Ptch}^{+/-}$mice $(\mathbf{F}$ and $\mathbf{H})$ compared with wild-type (E and G). J: qRT-PCR for Shh, Ptch1, and Gli1 in tch $^{++}-$versus wild-type mice $\left({ }^{* * * *} P<0.0001 ;{ }^{*} P<0.0187\right)$. Data are normalized against G6PDX and polr2a. Control values were set to $100 \%$ (dashed line); three tongue epithelia of $\mathrm{Ptch}^{+/-}$and control animals were analyzed for QPCR; SD is shown as SEM.

clarify if $\mathrm{Wnt} / \beta$-catenin signaling and Shh show a similar regulation in human tongue cancer as observed in $\mathrm{APC}$ min/+ and $\mathrm{Ptch}^{+/-}$mice, respectively, we analyzed hLSCC (World Health Organization, grades I to III). Paraffin sections were stained against cytokeratin 5/6 (CK5/6), $\beta$-catenin, Shh, and MIB1. Staining against CK5/6 confirmed the epithelial origin of the tumor cells, which infiltrated the tongue tissue in a typical cone-like manner (Figure 5A, E, and I). With increased tumor malignancy, epithelial differentiation of tumor cells was decreased, showing more frequently single CK5/6 positive cells dis-

seminating in the stromal tissue (Figure 5, E and I). $\beta$-Catenin showed distinct junctional staining between tumor cells in grade I hLSCC, whereas nuclear staining was regularly, but sparsely observed (Figure 5B). In grade II and grade III tumors, the junctional staining of $\beta$-catenin was lost at the invasive front of the tumor, whereas nuclear staining was increased (Figure 5, F and J). Shh staining intensity increased with tumor malignancy, and the localization essentially followed the nuclear $\beta$-catenin staining observed at the invading front (Figure 5C, G, and $\mathrm{K}$ ).

To evaluate the proliferative phenotype of the tumors, sections were stained against the proliferation marker MIB1. Proliferation notably increased from grade I to grade III tumors, which parallels the increase in nuclear $\beta$-catenin and the increase in Shh staining (Figure 5D, H, and L).

We speculated that the inhibitory effect of the Shh pathway on $\beta$-catenin-mediated signaling might be altered in lingual carcinoma, and we investigated the capacity of Shh to inhibit superTOP-FLASH reporter activation in a highly malignant hLSCC cell line (SCC25). ${ }^{23}$ Surprisingly, Shh, when transiently transfected into SCC25 cells, could significantly decrease Lef $\Delta \mathrm{N}-\beta C T A$ induced TOP-FLASH reporter activation in a comparable manner as in HEK293 cells ( ${ }^{\star} P<0.036$; Figure 5M).

Beside Shh also the Notch pathways has been described in the tongue epithelium and has been shown to interact with $\mathrm{Wnt} / \beta$-catenin signaling in various cell types and tissues. ${ }^{24}$

\section{Jagged-2 and Notch2 Are Up-Regulated in the Tongue Epithelium of APC min/+ Mice, Suppressing $\beta$-Catenin Signaling}

The Notch pathway has been suggested to negatively regulate $\beta$-catenin transcriptional activity in epithelial tissues, and, therefore, we investigated the expression pattern of Notch receptors and their Jagged ligands in APC min/+ and control mice. Quantitative RT-PCR demonstrated a specific up-regulation of Notch2 $\left({ }^{\star} P<0.0393\right)$ and its ligand JAG2 ( $\left.{ }^{* \star} P<0.0051\right)$ in APC ${ }^{\text {min/+ }}$ mice in respect to control littermates (Figure 6A). Furthermore, among the Notch target genes Hes1, Hey1, and Hey2, the latter was significantly up-regulated as revealed by qRT-PCR. The mRNA levels of Notch1 and Jagged-1 were not altered (Supplemental Figure S6, see http://ajp.amjpathol.org). In situ hybridization for JAG2 confirmed the up-regulation in the epithelium of the tongue from $\mathrm{APC}^{\mathrm{min} /+}$ mice compared to control littermates (Figure 6A). The sense control was devoid of any signal (data not shown). Also in tongues of $\mathrm{Ptch}^{+/-}$mice, Notch2 was significantly upregulated, whereas JAG2 was in tendency but not significantly altered by qRT-PCR and in situ hybridization (Supplemental Figure S6, see http://ajp.amjpathol.org).

To understand if Notch2 and/or JAG2 might have a direct effect on the signaling capacity of $\beta$-catenin, we transfected HEK293 cells with full length mouse Notch2 and rat JAG2 and monitored activation of the superTOPFLASH or mutant superFOP-FLASH reporter by the Lef $\Delta \mathrm{N}-\beta \mathrm{CTA}$ fusion construct. Lef $\Delta \mathrm{N}-\beta \mathrm{CTA}$ robustly in- 


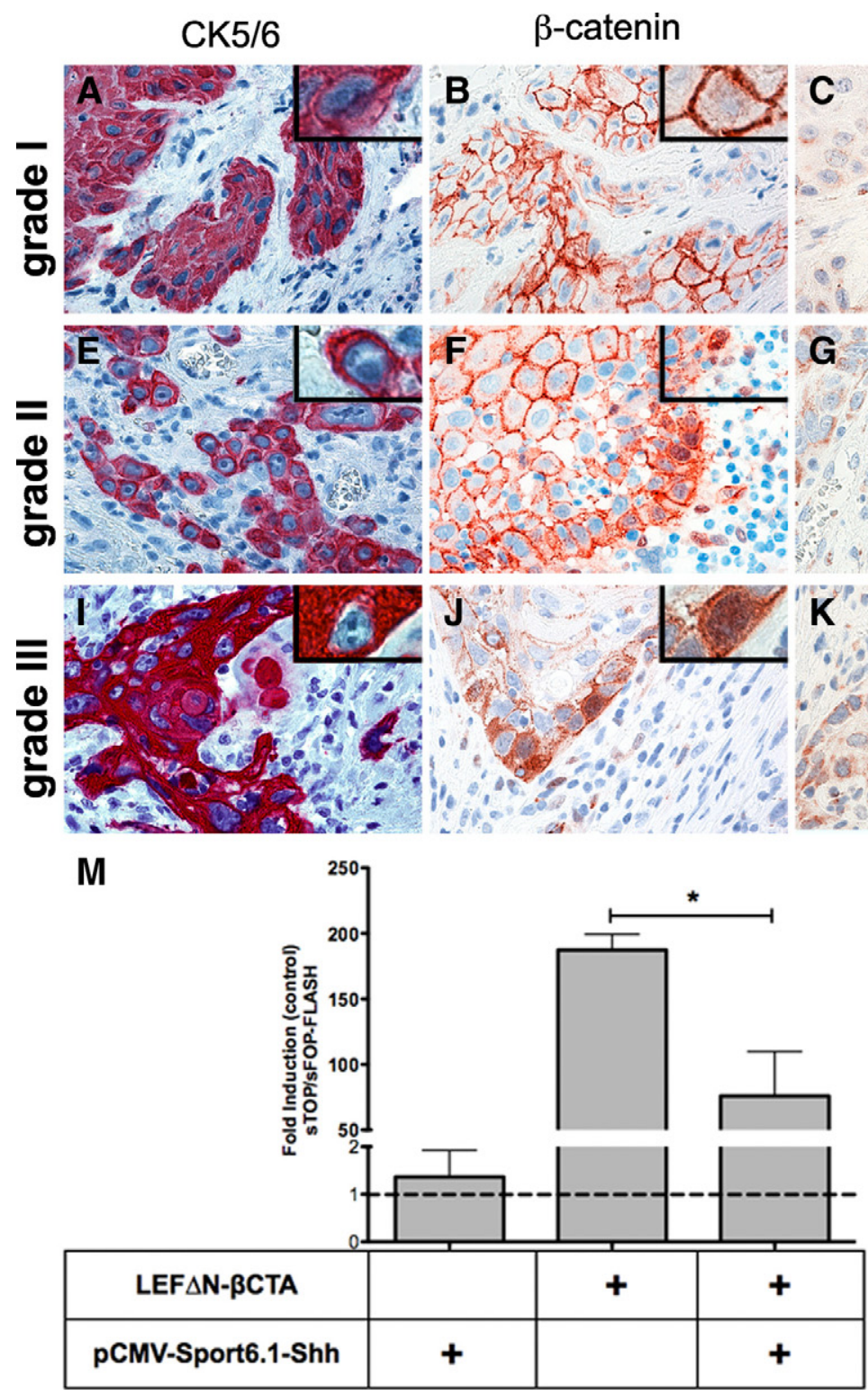

Shh
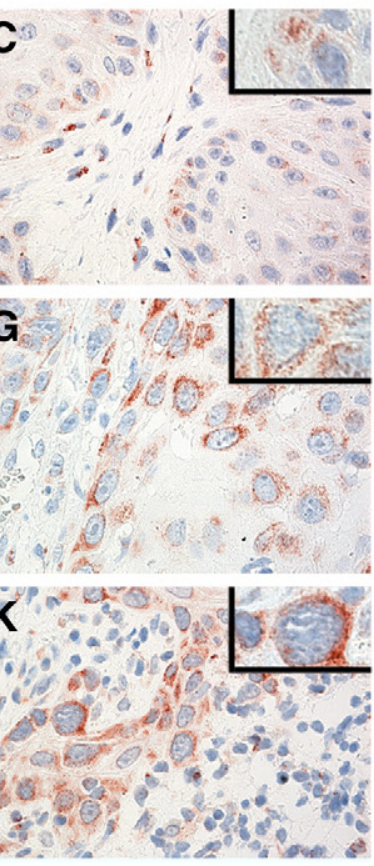

Figure 5. Shh and $\beta$-catenin in SCC of grades I to III. Invasive zone of human SCC section of grade I, grade II, and grade III tumors. A, E, and I: CK 5/6 staining reveals the epithelial nature of the tumor. Note the increased staining of single cells with increased tumor malignancy. $\mathbf{B}, \mathbf{F}$, and $\mathbf{J}: \beta$-catenin staining is predominantly junctional in low-grade tumors and shows increased frequency of nuclear localization in higher grades at the invasive front. Insets show higher magnification. $\mathbf{C}, \mathbf{G}$, and $\mathbf{K}$ : Increase in Shh staining along with increasing tumor grade. Note Shh positive cells at the invasive front of the tumor tissue. $\mathbf{D}, \mathbf{H}$, and $\mathbf{L}$ : Increase in MIB1 staining for proliferating cells along with increasing tumor malignancy parallels with tumor progression. Nuclear counter staining in blue; insets show higher magnification of MIB1 positive cells (World Health Organization grade I, $n=3$; II, $n=13$; III, $n=3)$. M: Human SCC 25 cells transiently transfected with sTOPFLASH or sFOP-FLASH reporter plasmids, stimulated with LEF $\Delta \mathrm{N}$ $\beta$ CTA co-transfected with or without the pCMV-Sport6.1-Shh plasmid $\left({ }^{*} P<0.0362\right)$. Experiments were performed in three individual experiments by using FuGene-HD (Roche); $\mathrm{SD}$ is shown as SEM. duced the superTOP-FLASH reporter (Figure 6B). Transfection of Notch2 into HEK293 cells did not significantly reduce TOP-FLASH activation by Lef $\Delta \mathrm{N}-\beta \mathrm{CTA}$, whereas JAG2 reproducibly decreased reporter activation $\left({ }^{* * *} P<\right.$ $0.0001)$. Double transfection of Notch2 and JAG2 also significantly reduced the superTOP-FLASH reporter $\left({ }^{\star \star \star} P<0.0001\right)$. To investigate whether the effect of JAG2 is dependent on $\gamma$-secretase-mediated cleavage of the Notch intracellular domain, we blocked the $\gamma$-secretase activity with DAPT. Interestingly, even in the presence of DAPT, JAG2 effectively inhibited the superTOP-FLASH reporter $\left({ }^{* \star} P<0.0006\right)$, suggesting that JAG2 acts independently of the canonical Notch pathway. Expression and biological activity of transfected constructs were confirmed by Western blot analysis (Figure 6B) and TP1$\mathrm{RBPJ}_{\kappa}$ luciferase reporter assay (Supplemental Figure S7, see http://ajp.amjpathol.org), respectively.

To understand if JAG2 is able to effectively inhibit $\beta$-catenin signaling in hLSCC, we subjected SCC25 cells to the superTOP-FLASH reporter assay. Interestingly, neither Notch2 nor JAG2 had a significant effect on reporter activation (Figure 6C), indicating that the JAG2-medited suppression of the Lef $\Delta \mathrm{N}-\beta \mathrm{CTA}$ transcriptional activity observed in HEK293 cells is not functional in SCC25.

\section{Discussion}

In the present article we provide evidence for the concerted regulation of canonical, $\beta$-catenin driven Wnt signaling in the adult tongue epithelium by the Shh and the Notch pathway, and that this regulatory circuit is disturbed in the human squamous cell carcinoma cell line SCC25

BAT-gal reporter mice and nuclear staining for $\beta$-catenin revealed Wnt/ $\beta$-catenin signaling in single cells of all papilla types in the adult tongue epithelium, suggesting that the Wnt pathway is involved in physiological cell 
A

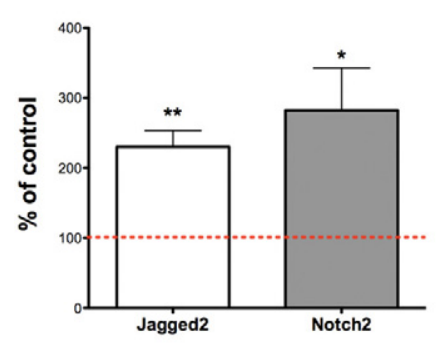

B
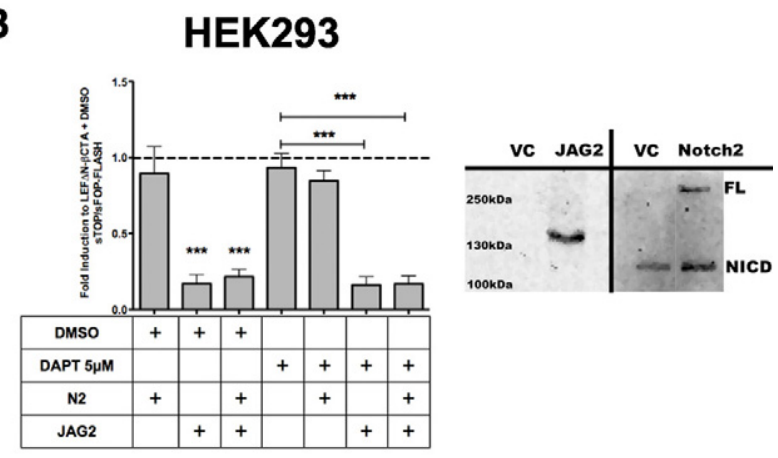

C

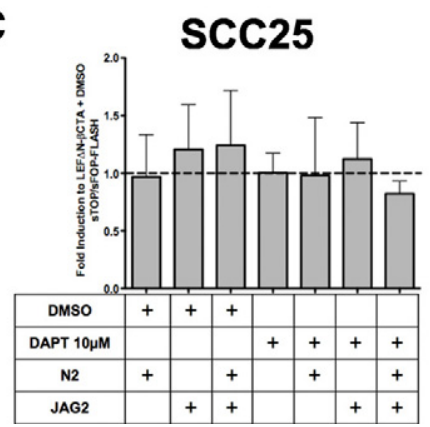

Figure 6. Jagged-2 and Notch2 are up-regulated in the tongue epithelium of APC ${ }^{\mathrm{min} /+}$ mice, suppressing $\beta$-catenin signaling. A: qRT-PCR of APC ${ }^{\mathrm{min} /+}$ versus wild-type mice tongue epithelium showed an up-regulation of the Notch pathway genes Jagged $2\left({ }^{* * *} P<0.0051\right)$ and Notch2 $\left({ }^{*} P<0.0393\right)$. In situ hybridization for Jagged 2 verified increased mRNA in $\mathrm{APC}^{\mathrm{min} /+}$ mice versus wild-type. B: sTOP/sFOP-FLASH reporter transiently transfected in HEK293; stimulation with $50 \mathrm{ng}$ LEF $\Delta \mathrm{N}-\beta C T$ A, co-transfected with $300 \mathrm{ng}$ Notch 2 or 600 ng Jagged2 (**** $P<0.0001)$ or both $\left({ }^{* * * * *} P<0.0001\right)$. Reduction of the sTOP-FLASH compared with LEF $\Delta \mathrm{N}-\beta \mathrm{CTA}$ unstimulated as control (dashed line) is not influenced by the Presenellin inhibitor DAPT $(10 \mu \mathrm{mol} / \mathrm{L}$; $\left.{ }^{* * * *} P<0.0006\right)$. The assay was performed in five individual experiments; SD is shown as SEM. Western blot analysis of Jagged2 and Notch2 over expression in HEK293 cells. Note the two forms of Notch2; upper band shows full length (FL), and the lower band shows Notch intracellular domain on a $7 \%$ SDS-polyacrylamide gel electrophoresis. C: Transient transfected SCC25 cells with the sTOP/sFOP-FLASH reporter and the same amounts of LEF $\Delta \mathrm{N}-\beta \mathrm{CTA}$, Jagged2, and Notch2 as indicated in $\mathbf{B}$. The assay was performed in three individual experiments; SD is shown as SEM.

turnover from stem/precursor cells, similar to the situation in the hair bulge and the intestine. ${ }^{25-27}$ It has previously been reported that the Shh pathway is active also in the adult mouse tongue, suggesting a role in tongue epithelial/taste bud maintenance. ${ }^{28}$ Together these findings suggest that in the adult tongue Wnt/ $\beta$-catenin is upstream of Shh and that Shh negatively regulates Wnt signaling in tongue epithelial/taste bud maintenance.

It is well established in other epithelial stem/progenitor cell compartments, such as in the hair bulge and the

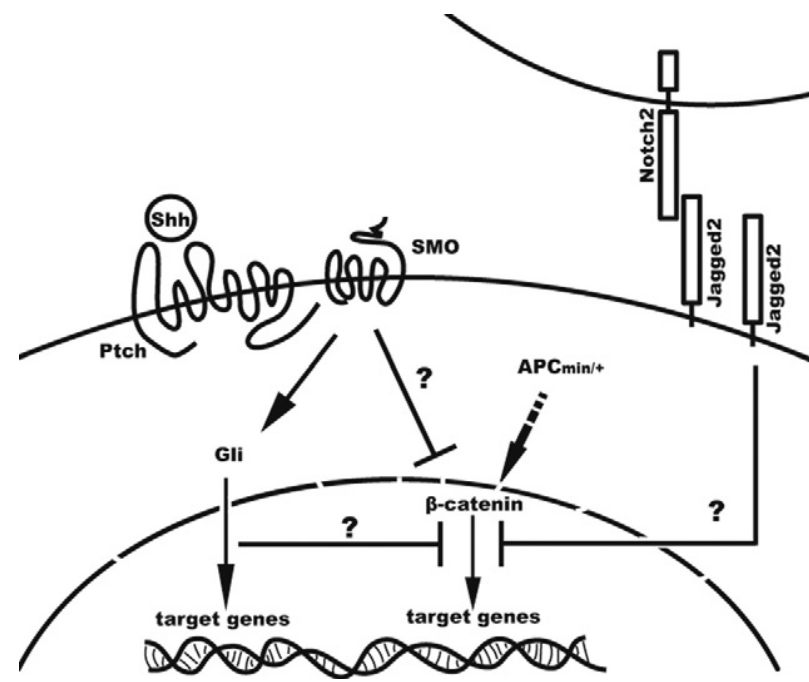

Figure 7. Interaction scheme of Shh and activated $\beta$-catenin signaling. Schematic illustration of the hypothesized inhibition of $\beta$-catenin by canonical Shh signaling together with Jagged2-Notch2. Left side: If Shh binds to Ptch, it looses its inhibitory effect on SMO. This activates the Gli proteins for target gene translation (left side). The $\mathrm{APC}$ mutation in $\mathrm{APC}^{\mathrm{min} /+}$ leads to accumulation of cytosolic and nuclear $\beta$-catenin and leads to Wnt-specific target gene translation (middle). The activation of the Shh signaling is able to inhibit $\beta$-catenin downstream of the degradation complex. It is unknown whether this inhibition mechanism works through a novel pathway initiated by the receptor complex Ptch/SMO or takes place further downstream. Right side: JAG2 might be a second control mechanism for $\beta$-catenin via an unknown mechanism, as canonical Notch signaling is not required.

intestinal crypts, that Wnt signaling activity above a physiological threshold is causative for the formation of neoplasia. ${ }^{1,29}$ Hence a feedback control of the canonical Wnt activation is crucial for physiological tissue maintenance. Here we show that constitutive, dominant activation of $\beta$-catenin transcriptional activity in heterozygous APC mutant mice (APC ${ }^{\mathrm{min} /+}$ ) leads to the expression of Shh and the Shh target gene Ptch1 in the epithelium of the tongue (Figure 7). The tongues of $\mathrm{APC}^{\mathrm{min} /+}$ mice remain phenotypically normal throughout life, and no case of neoplasia could be observed before the animals died of intestinal carcinoma at around 5 months of age. We provide evidence that this is likely due to Shh signaling that in turn diminishes nuclear $\beta$-catenin and its transcriptional activation evidenced in superTOP-FLASH reporter assays in vitro and in Ptch $1^{+/-}$mice in vivo. Importantly, the inhibition of $\beta$-catenin signaling does not involve proteasomal degradation of $\beta$-catenin, as suggested by the use of the nondegradeable chimeric protein Lef $\Delta N$ $\beta$ CTA. ${ }^{22}$ This shows for the first time that ligand-dependent Shh signaling regulates $\beta$-catenin dependent transcription at the nuclear level.

This is in accordance with previous reports, showing that the Hh pathway, in particular Indian hedgehog, may negatively regulate Wnt signaling in normal colonic epithelial cells. ${ }^{30}$ In this regard it is noteworthy that the Hh signalingtransducing protein $\mathrm{SMO}$ is up-regulated in colonic polyps and correlates with tumor progression in $\mathrm{APC}^{\mathrm{min} /+}$ mice. ${ }^{31}$ These at first glance contradictory results strongly speak in favor of tissue specificity of the Shh pathway. Indeed, the Shh target Ptch1 was significantly up-regulated in the epi- 
thelium of $\mathrm{APC}$ min/+ tongues (Figure 2G) but not in the colon, neither in normal nor in polyp areas. ${ }^{31}$

Furthermore, the finding that the SMO antagonist cyclopamine abrogates the inhibitory effect of Shh on the Wnt/ $\beta$-catenin pathway in HEK293 cells in vitro (Supplemental Figure S4, see http://ajp.amjpathol.org) or during tongue and taste bud development ${ }^{32}$ supports the interpretation that Shh signaling activity is required in the tongue epithelium.

Although activating mutations in the $\beta$-catenin pathway are only found in a subset of hLSCC, ${ }^{33-35}$ nuclear localization of $\beta$-catenin and hence increased transcriptional activity are regularly found at the invasive front of hLSCC (Figure 5 ). Nuclear $\beta$-catenin increased with tumor progression, which was reported also for carcinoma of other origin, and to be independent of mutational activation. ${ }^{36,37}$ Concomitantly, Shh expression was increased suggesting that also in hLSCC Wnt/ $\beta$-catenin acts upstream of Shh and becomes increasingly up-regulated with tumor malignancy. We speculated initially that the inhibitory function of Shh signaling might be impaired in hLSCC, leading to $\beta$-catenindriven tumor progression and invasion. Surprisingly this was not the case, as Shh effectively inhibited Lef $\Delta \mathrm{N}-\beta C T$ Ainduced superTOP-FLASH reporter activation in the highly malignant hLSCC cell line SCC25.

In addition to the Shh pathway also the Notch pathway may potentially play a role in suppressing excessive Wnt signaling during embryonic development and in adult tissue homeostasis. ${ }^{38}$ As JAG2 and Notch2 were detected to be significantly up-regulated in $\mathrm{APC}^{\mathrm{min} /+}$ mice. This finding fits with the report that Notch2 is an $\mathrm{Hh}_{\text {target }}{ }^{39,40}$ and might be up-regulated on Shh signaling. JAG2 instead was significantly up-regulated in the tongue epithelium of $\mathrm{APC}$ min/+ mice but not in Ptch $^{+/-}$mice (Supplemental Figure S6, see http://ajp.amjpathol.org), which might support the interpretation that JAG2, similar to JAG1, ${ }^{41,42}$ is regulated by $\beta$-catenin rather than by Shh.

We tested the capacity of JAG2 and Notch2 to regulate superTOP-FLASH reporter activation in HEK293 or SCC25 cells. The finding that HEK293 but not SCC25 cells were responsive for JAG2-mediated inhibition of the superTOPFLASH reporter suggests that JAG2 function is impaired in SCC25 cells. Interestingly, co-transfection of Notch2 with JAG2 did not rescue the inhibitory effect of JAG2 on the superTOP-FLASH reporter, suggesting a Notch-independent function of JAG2 in this respect. This interpretation was corroborated by the insensitivity of the JAG2 effect on the superTOP-FLASH reporter for the $\gamma$-secretase inhibitor DAPT. Although, it has been reported for Notch1 that Notch1-ICD can suppress $\beta$-catenin transcriptional activity and tumorigenic potential of SCC cells, ${ }^{43}$ Notch2 might have opposing functions in the tongue. ${ }^{44}$

Our data show for the first time that ligand-mediated activation of the Shh pathway regulates $\mathrm{Wnt} / \beta$-catenin activity at the transcriptional level in adult tongue epithelial cells in vivo and in HEK293 and SCC25 tumor cells in vitro. Under physiological conditions, the bona fide Wnt/ $\beta$-catenin targets Shh and JAG2 may act synergistically to counterbalance elevated $\beta$-catenin stabilization in the tongue to tolerable levels. This might explain why APC min/+ mice do not develop LSCC during their lifetime. Likely, epithelial cells need to accumulate additional mutations to transform into carcinoma cells.

Supporting this hypothesis, we show that the highly malignant hLSCC cell line SCC25 is not responsive for JAG2-mediated suppression of $\beta$-catenin signaling, which might partially explain that high grade hLSCC frequently exhibit nuclear $\beta$-catenin in the migrating front of the tumor. Interestingly, the increase in nuclear $\beta$-catenin as well as expression of Shh with tumor grade is accompanied by an increase in cell proliferation, suggesting that $\mathrm{Wnt} / \beta$-catenin signaling is important for LSCC progression. Although we could show that Shh retains its suppressive activity on $\beta$-catenin signaling in SCC25 cells, evidence in basal cell carcinoma (BCC) points to the possibility that during tumor development in vivo, Shh signaling may act tumorigenic in conjunction with ligand driven $\mathrm{Wnt} / \beta$-catenin signaling. ${ }^{45}$

\section{Conclusions}

In conclusion, accumulating evidence points to a role of Wnt and Shh, together with Notch and BMP, as key regulators of adult stem cells and that the imbalance of the signaling circuitry is indicative for tumor formation and progression. ${ }^{46}$ Dominant activation of $\beta$-catenin transcriptional activity in APC ${ }^{\mathrm{min} /+}$ mice leads to a significant up-regulation of Shh as well as of JAG2, which together diminish $\beta$-catenin signaling in a Shh signaling-dependent and a JAG2/Notch2 signaling-independent manner to tolerable levels. This is the first evidence that the Hh pathway and the Notch pathway member JAG2 cooperatively suppress $\mathrm{Wnt} / \beta$-catenin signaling to maintain tissue integrity in the tongue epithelium. This finding may help to define new drug targets for cancer therapy in a tissue- and cell-specific manner.

\section{Acknowledgments}

The Jagged2 in situ probe has been provided by Verdon Taylor (University of Sheffield, Sheffield, UK). The superTOP-flash reporter has been kindly provided by Randall T. Moon (University of Washington, Seattle, WA). The LEF $\Delta \mathrm{N}$ - $\beta$ CTA construct has been kindly provided by Andreas Hecht (Albert-Ludwigs-University Freiburg, Germany). The pcDNA3.1-mGli1, $8 \times$ 3'Gli-BS $551 \mathrm{Lucll}$ and $8 \times 3^{\prime}$ GliM3-BS 851 Lucll are generous gifts from Dr. Hiroshi Sasaki (Center of Developmental Biology, RIKEN Kobe, Japan). We thank Janina Drynski for excellent technical support.

\section{References}

1. Clevers $\mathrm{H}$ : Wnt/beta-catenin signaling in development and disease Cell 2006, 127:469-480

2. Ingham PW: Hedgehog signalling. Curr Biol 2008, 18:R238-R241

3. Harris TJ, Peifer M: Decisions, decisions: beta-catenin chooses between adhesion and transcription. Trends Cell Biol 2005, 15:234-237

4. Scheller M, Huelsken J, Rosenbauer F, Taketo MM, Birchmeier W Tenen DG, Leutz A: Hematopoietic stem cell and multilineage defects 
generated by constitutive beta-catenin activation. Nat Immunol 2006, 7:1037-1047

5. Harada N, Tamai Y, Ishikawa T, Sauer B, Takaku K, Oshima M, Taketo MM: Intestinal polyposis in mice with a dominant stable mutation of the beta-catenin gene. EMBO J 1999, 18:5931-5942

6. Maretto S, Cordenonsi M, Dupont S, Braghetta P, Broccoli V, Hassan AB, Volpin D, Bressan GM, Piccolo S: Mapping Wnt/beta-catenin signaling during mouse development and in colorectal tumors. Proc Natl Acad Sci USA 2003, 100:3299-3304

7. Reya $\mathrm{T}$, Clevers $\mathrm{H}$ : Wnt signalling in stem cells and cancer. Nature 2005, 434:843-850

8. Borycki A, Brown AM, Emerson CP Jr: Shh and Wnt signaling pathways converge to control Gli gene activation in avian somites. Development 2000, 127:2075-2087

9. Jia J, Jiang J: Decoding the Hedgehog signal in animal development. Cell Mol Life Sci 2006, 63:1249-1265

10. Cohen MM: The hedgehog signaling network. Am J Med Genet A 2003, 123A:5-28

11. Goodrich LV, Milenkovic L, Higgins KM, Scott MP: Altered neural cell fates and medulloblastoma in mouse patched mutants. Science 1997, 277:1109-1113

12. Hall JM, Hooper JE, Finger TE: Expression of sonic hedgehog, patched, and Gli1 in developing taste papillae of the mouse. J Comp Neurol 1999, 406:143-155

13. Nakayama A, Miura H, Shindo Y, Kusakabe $Y$, Tomonari H, Harada S: Expression of the basal cell markers of taste buds in the anterior tongue and soft palate of the mouse embryo. J Comp Neurol 2008, 509:211-224

14. Mistretta CM, Liu HX, Gaffield W, MacCallum DK: Cyclopamine and jervine in embryonic rat tongue cultures demonstrate a role for Shh signaling in taste papilla development and patterning: fungiform papillae double in number and form in novel locations in dorsal lingual epithelium. Dev Biol 2003, 254:1-18

15. Iwatsuki K, Liu HX, Grunder A, Singer MA, Lane TF, Grosschedl R, Mistretta CM, Margolskee RF: Wnt signaling interacts with Shh to regulate taste papilla development. Proc Natl Acad Sci USA 2007, 104:2253-2258

16. Liu F, Thirumangalathu S, Gallant NM, Yang SH, Stoick-Cooper CL, Reddy ST, Andl T, Taketo MM, Dlugosz AA, Moon RT, Barlow LA, Millar SE: Wnt-beta-catenin signaling initiates taste papilla development. Nat Genet 2006, 39:106-112

17. Okubo T, Pevny LH, Hogan BL: Sox2 is required for development of taste bud sensory cells. Genes Dev 2006, 20:2654-2659

18. Liebner S, Cattelino A, Gallini R, Rudini N, Iurlaro M, Piccolo S, Dejana E: Beta-catenin is required for endothelial-mesenchymal transformation during heart cushion development in the mouse. J Cell Biol 2004, 166:359-367

19. Sambrook J, Fritsch AF, Maniatis T: Molecular cloning: a laboratory manual. Edited by CS Harbor. New York, Cold Spring Harbor Laboratory, 1989

20. Dyer BW, Ferrer FA, Klinedinst DK, Rodriguez R: A noncommercial dual luciferase enzyme assay system for reporter gene analysis. Anal Biochem 2000, 282:158-161

21. Sasaki H, Hui C, Nakafuku M, Kondoh H: A binding site for Gli proteins is essential for HNF-3beta floor plate enhancer activity in transgenics and can respond to Shh in vitro. Development 1997, 124:1313-1322

22. Vleminckx K, Kemler R, Hecht A: The C-terminal transactivation domain of beta-catenin is necessary and sufficient for signaling by the LEF-1/beta-catenin complex in Xenopus laevis. Mech Dev 1999, 81:65-74

23. Rheinwald JG, Beckett MA: Tumorigenic keratinocyte lines requiring anchorage and fibroblast support cultures from human squamous cell carcinomas. Cancer Res 1981, 41:1657-1663

24. Hayward P, Brennan K, Sanders P, Balayo T, DasGupta R, Perrimon N, Martinez Arias A: Notch modulates Wnt signalling by associating with Armadillo/beta-catenin and regulating its transcriptional activity. Development 2005, 132:1819-1830

25. He XC, Yin T, Grindley JC, Tian Q, Sato T, Tao WA, Dirisina R, Porter-Westpfahl KS, Hembree M, Johnson T, Wiedemann LM, Barrett TA, Hood L, Wu H, Li L: PTEN-deficient intestinal stem cells initiate intestinal polyposis. Nat Genet 2007, 39:189-198

26. Katoh M, Katoh M: WNT signaling pathway and stem cell signaling network. Clin Cancer Res 2007, 13:4042-4045
27. Blanpain C, Horsley V, Fuchs E: Epithelial stem cells: turning over new leaves. Cell 2007, 128:445-458

28. Miura H, Kusakabe $Y$, Sugiyama C, Kawamatsu M, Ninomiya $Y$, Motoyama J, Hino A: Shh and Ptc are associated with taste bud maintenance in the adult mouse. Mech Dev 2001, 106:143-145

29. Chien AJ, Conrad WH, Moon RT: A Wnt survival guide: from flies to human disease. J Invest Dermatol 2009, 129:1614-1627

30. Van Den Brink GR, Bleuming SA, Hardwick JCH, Schepman BL, Offerhaus GJ, Keller JJ, Nielsen C, Gaffield W, Van Deventer SJH, Roberts DJ, Peppelenbosch MP: Indian Hedgehog is an antagonist of Wnt signaling in colonic epithelial cell differentiation. Nat Genet 2004, 36:277-282

31. Arimura S, Matsunaga A, Kitamura T, Aoki K, Aoki M, Taketo M: Reduced level of smoothened suppresses intestinal tumorigenesis by down-regulation of Wnt signaling. Gastroenterology 2009, 137:629-638

32. Liu HX, Maccallum DK, Edwards C, Gaffield W, Mistretta CM: Sonic hedgehog exerts distinct, stage-specific effects on tongue and taste papilla development. Dev Biol 2004, 276:280-300

33. Gasparoni A, Chaves A, Fonzi L, Johnson GK, Schneider GB, Squier CA: Subcellular localization of beta-catenin in malignant cell lines and squamous cell carcinomas of the oral cavity. J Oral Pathol Med 2002, 31:385-394

34. Gasparoni A, Fonzi L, Schneider GB, Wertz PW, Johnson GK, Squier CA: Comparison of differentiation markers between normal and two squamous cell carcinoma cell lines in culture. Arch Oral Biol 2004, 49:653-664

35. Yang F, Zeng Q, Yu G, Li S, Wang CY: Wnt/beta-catenin signaling inhibits death receptor-mediated apoptosis and promotes invasive growth of HNSCC. Cell Signal 2006, 18:679-687

36. Bandapalli OR, Dihlmann S, Helwa R, Macher-Goeppinger S, Weitz J, Schirmacher P, Brand K: Transcriptional activation of the beta-catenin gene at the invasion front of colorectal liver metastases. J Pathol 2009, 218:370-379

37. Mani M, Carrasco DE, Zhang Y, Takada K, Gatt ME, Dutta-Simmons J, Ikeda H, Diaz-Griffero F, Pena-Cruz V, Bertagnolli M, Myeroff LL, Markowitz SD, Anderson KC, Carrasco DR: BCL9 promotes tumor progression by conferring enhanced proliferative, metastatic, and angiogenic properties to cancer cells. Cancer Res 2009, 69: 7577-7586

38. O'Neill CF, Urs S, Cinelli C, Lincoln A, Nadeau RJ, León R, Toher J Mouta-Bellum C, Friesel RE, Liaw L: Notch2 signaling induces apoptosis and inhibits human MDA-MB-231 xenograft growth. Am J Pathol 2007, 171:1023-1036

39. Dakubo GD, Mazerolle CJ, Wallace VA: Expression of Notch and Wnt pathway components and activation of Notch signaling in medulloblastomas from heterozygous patched mice. J Neurooncol 2006, 79:221-227

40. Hallahan AR, Pritchard JI, Hansen S, Benson M, Stoeck J, Hatton BA, Russell TL, Ellenbogen RG, Bernstein ID, Beachy PA, Olson JM: The SmoA1 mouse model reveals that notch signaling is critical for the growth and survival of sonic hedgehog-induced medulloblastomas. Cancer Res 2004, 64:7794-7800

41. Estrach S, Ambler CA, Lo Celso C, Hozumi K, Watt FM: Jagged 1 is a beta-catenin target gene required for ectopic hair follicle formation in adult epidermis. Development 2006, 133:4427-4438

42. Rodilla V, Villanueva A, Obrador-Hevia A, Robert-Moreno A, FernandezMajada V, Grilli A, Lopez-Bigas N, Bellora N, Alba MM, Torres F, Dunach M, Sanjuan X, Gonzalez S, Gridley T, Capella G, Bigas A, Espinosa L: Jagged1 is the pathological link between Wnt and Notch pathways in colorectal cancer. Proc Natl Acad Sci USA 2009, 106:6315-6320

43. Duan L, Yao J, Wu X, Fan M: Growth suppression induced by Notch1 activation involves $\mathrm{Wnt} /$ beta-catenin down-regulation in human tongue carcinoma cells. Biol Cell 2006, 98:479-490

44. Fan X, Mikolaenko I, Elhassan I, Ni X, Wang Y, Ball D, Brat DJ, Perry A, Eberhart CG: Notch1 and notch2 have opposite effects on embryonal brain tumor growth. Cancer Res 2004, 64:7787-7793

45. Yang H, Andl T, Grachtchouk V, Wang A, Liu J, Syu LJ, Ferris J, Wang TS, Glick AB, Millar SE, Dlugosz AA: Pathological responses to oncogenic Hedgehog signaling in skin are dependent on canonical Wnt/beta-catenin signaling. Nat Genet 2008, 40:1130-1135

46. Mizrak D, Brittan M, Alison M: CD133: molecule of the moment. J Pathol 2008, 214:3-9 